\title{
Class Formation and Localism in an Emerging Bureaucracy: British Bank Workers, 1880-1960
}

\author{
MIKE SAVAGE, KATHERINE STOVEL AND PETER BEARMAN
}

\section{Space, networks and class formation}

In recent years, scholars have paid renewed attention to the complex relationship between space and class formation. While most research has been oriented towards the emergence of the working class during early industrial capitalism (cf. Katznelson and Zollberg, 1986), the development of a class of white-collar labourers in the nineteenth and twentieth centuries has also garnered interest. Many have characterized this process as the simple rise of the cosmopolitan spiralist over the local burgess, focusing on the erosion of Victorian dependence on local business and urban public networks, and the emergence, by the mid-twentieth century, of highly mobile, 'spiralist' middle classes whose geographic mobility was a main dynamic of internal migration. ${ }^{1}$ Thus, historians have emphasized the ability of the Victorian middle class to define themselves as cohesive groups by colonizing urban space and by creating a varied array of face-to-face institutional forms which allowed their social presence to be registered (see Smith, 1982; Daunton, 1989; Morris, 1990). In this view, voluntary associations, churches and clubs were the forcing ground of the Victorian middle class. By the period after 1945, however, the existence of a spatially mobile middle class had become such an 'obvious' fact that some sociologists had even begun to regard it as a necessary concomitant of an efficient, modern society. ${ }^{2}$ In place of the locally attached bourgeoisie, this newly mobile cosmopolitan class was thought to be largely detached from local environments, moved frequently between places at the whim of their employer, and had little in common with the rump of the old local business groups. ${ }^{3}$

1 In the most thorough British study of the period, Johnson et al. (1974) found that around 50\% of people moving location did so for job reasons and, of these, a very high proportion were middle-class personnel moving to better jobs. As many as $72 \%$ of those who had moved for job reasons were professional, managerial or administrative employees, and they concluded that 'labour migration for job reasons was therefore a very positive agent of spiralism for the middle classes' (ibid.: 565). See the broader discussion in Savage (1988). Other studies pointing to the significance of the spiralists include, in the American context, Whyte (1957), Blau and Duncan (1967) and, in Britain, Musgrove (1963) and Watson (1960). In the British case, the community studies of Banbury (Stacey, 1960) and Glossop (Birch, 1959) were an important impetus to this discovery.

2 This was especially true amongst American functionalists. See, for instance, Parsons (1959).

3 Colin Bell's (1968) study of Swansea is an especially clear example of this. He claimed that the spiralist middle class had very different networks and attachments than did the local middle class. 
More generally, beginning with Engels' pioneering study of the working class in Victorian Manchester and proceeding through the community studies of Lynd and Lynd (1929), Dennis et al. (1956), Frankenberg (1966) and others, many observers of emerging social classes have noted the particular spatial conditions in which new classes are forged. Largely through careful case studies, these scholars have emphasized that the process of class formation is fundamentally anchored in urban and local contexts, and that classes develop unevenly even within political boundaries. By the mid-1980s, however, this view had largely given way to the 'political arithmetic' tradition that treated classes as entities existing primarily at the national level. Exploiting the national sample survey as the new linchpin of orthodox social science, this approach elided the issue of uneven development across space in favour of comparative study of national class structures (e.g. Wright, 1985; 1996; Erikson and Goldthorpe, 1992; Evans et al., 1999). Against this current trend some have recommended reviving the old notion that class formation is a local process that must be studied in relevant local and urban environments (e.g. Katznelson, 1988). This challenge has been taken up in several systematic studies of class formation in various local environments, sometimes in a comparative frame (for instance Savage, 1987; Morris, 1990; Koditschek, 1994; Gould, 1995).

Buried beneath the theoretical disputes rest methodological differences. Those interested in the local nature of class formation often deploy qualitative methods of spatially defined areas (cities, neighbourhoods) for community studies of particular cases, while those with a more macro-orientation utilize statistical models of survey data to examine the extent to which class is a national phenomenon. To a large extent this has resulted in a methodological 'stand off' between class analysts who conceptualize the theoretical issues in very different ways (see Crompton, 1998, and Savage, 2000, for discussion).

We enter this fray on both conceptual and methodological grounds. Conceptually, we build from the insights of recent social theorists who argue that we should not reify space on any scale, but rather treat it relationally (e.g. Lefebvre, 1991). This approach recognizes that studies that treat cities or localities simply as 'containers' for diverse processes of class formation are little different from those that treat nations in equivalent fashion, except that the spatial scale tends to be smaller. In contrast, thinking about the relational aspects of the class formation process alerts us to the way that emerging classes are forged by new patterns of connection between persons and positions in particular places. In this respect, the class formation process is not just rooted in space, but rather occurs through space, and can be revealed by examining shifting relationships to place and through unpacking the 'structure of flows'.

By way of comparison, it is striking that variants of this basic argument have been developed by theorists of ethnicity who have pointed to the role of diaspora - the movements of ethnic groups between different locales - in shaping the key contours of ethnic identity (see, e.g., Gilroy, 1994). This conceptual approach can easily be extended to the study of class formation. For example, it is possible to contrast the British aristocracy who moved in an ambit between court, country seat and county town (see Davidoff, 1973) with the bourgeoisie who drew on their urban power bases to define a distinct urban public realm (Morris, 1990) or the working class who drew on the practices of the tramping artisan (Southall, 1990). Understanding the relations between these classes involves exploring their different spatial organization. Similarly, we might focus on the extent to which increases in the mobility of labour facilitated the rise of trade unions and other collective traditions that linked traditional labour markets.

Despite the theoretical appeal of this renewed interest in relational networks, it is, of course, possible to over-emphasize the significance of fluidity in the class-formation process. As discussed in the introduction to this special issue, the risk is that the role of specific places and localities may be eclipsed as attention centres on more general processes of mobility and connection. Hence, it is essential to tend to the persistence of 
localism even as broader spatial networks play a more central role, and to examine the articulation of the local within the mobile.

Our aim in this article is to revisit the idea of a simple transition between local and national middle classes on two fronts. Using a detailed case study of Lloyds Bank, ${ }^{4}$ we examine how localized concerns persisted even within the organizations that served as the engines for the newly mobile workers. We then show that, while the middle classes did, in fact, become more mobile, this mobility was not unfettered by geography or local interests. Drawing upon both archival records and individual level data on job-related geographic mobility among workers employed at Lloyds Bank between 1880 and 1960, we exploit the richness of organizational data that provides an unusual opportunity to examine key spatial aspects of the class-formation process.

Our analyses highlight the continued importance of local interests, reflected in both individual experiences and in organizational structures, even as the organization and the class of workers in its employ became self-consciously 'national'. We argue that the creation of a national bank structure involved a complex balancing act between winning credibility in local communities and centralizing effectively. Lloyds managed to balance these rather contradictory needs by organizing mobility around specific kinds of categorical (Tilly, 1998), ascriptive criteria: here we focus on the extent to which local and regional origins organized mobility through the bank worker's career. ${ }^{5}$

We find that despite rapid growth and expansion, a fully fledged national labour market did not develop at Lloyds during the early and mid-twentieth century. In our conclusion we generalize from these specific findings to reflect on how an organization's ability to accommodate and incorporate local interests may facilitate its success as a national institution, and, more broadly, on the relationship between place and class formation.

\section{Local banking cultures}

British banks are a particularly interesting case to study in light of debates about the nature of class formation, since, on the surface, they appear to present a classic case of straightforward bureaucratization. The roots of banking lie in the localist, gentlemanly culture seen by historians as a key feature of British social development (Cain and Hopkins, 1992); during the Victorian period, bankers were regarded as critical members of local status communities. Prior to the mid-nineteenth century, most banks were privately and locally owned, employed local staff and played a key role in local affairs. As one leading bank authority wrote in 1902: 'Customers will hardly care to establish relations with managers who will be migratory as so many Bedouins’ (Rae, 1902: 166).

Despite this heritage, by the early twentieth century branch banking had developed into one of the most modern sectors of the British economy, with workers who epitomized the mobile middle class frequently moving from branch to branch in order to further their careers. In contrast to the US and many European countries, the British clearing banks were centralized and fully-integrated national bureaucracies by the end of the Great War. Of private-sector companies, only the railway companies could claim to have espoused the bureaucratic model with such thoroughness, but since the railway

4 This study was part of an ESRC funded project, 'Pathways and prospects: the development of the modern bureaucratic career, 1875[-]1950', ref R000232803, directed by Andrew Miles (University of Birmingham), Mike Savage and David Vincent (University of Keele).

5 Another important ascriptive criteria was gender. Women began to be employed at Lloyds in the 1920s and were used until the post-second-world-war period in the large urban branches, where they worked on new book-keeping machines. However, women were only allowed to work in specific female grades which had little prospect for either geographic or occupational mobility; they were typically let go when they married. For details of these career routes see Savage (1993). 
companies were regionally based, they were not truly national concerns as early as the 'big five' banks.

\section{Lloyds Bank}

Like all the British clearing banks, the roots of Lloyds Bank lay in the local business communities of the provinces, in this case the West Midlands. Originally founded as a Quaker bank in Birmingham in 1765, Lloyds remained a privately-owned family firm without branches until the 1860s. Following the legalization of joint-stock companies, Lloyds became a joint-stock bank and began to grow, largely by absorbing other banks. Until the 1880s, however, Lloyds' expansion took place entirely in the West Midlands; the bank's major breakthrough came in 1884 when it absorbed its first London bank, and became known as Barnet's, Hoares, Hanbury's and Lloyds. This merger allowed the Lloyds' family a seat in the London Banker's Clearing House (a key site for banking activity) and gave the bank entry to the lucrative London and international markets. Lloyds continued to grow through amalgamation and expansion, with its major growth occurring between 1890 and 1918 as it absorbed local banks from throughout England and Wales (see Sayers, 1957; Winton, 1980). Between 1865 and 1923, Lloyds absorbed over 50 different banks, some bringing just a single branch into the Lloyds' structure, while others brought highly developed systems of branch banking.

Because it absorbed myriad local offices, each with important relationships to local business communities, the path by which Lloyds grew into a national concern created particular operating issues. There were two ways in which the newly national bank could deal with its myriad local offices and business communities: either by subordinating noninstrumental local interests to uniform national procedures; or by accommodating them. On the face of it, Lloyds appeared to opt for the former path, instituting many features of a classic, centralized bureaucracy. For example, book-keeping procedures in every branch were harmonized to central rules, branch managers were required to follow explicit, codified procedures detailing the amount of money they were authorized to lend, and professional managers superseded the direct power of the Lloyds' family. Furthermore, Lloyds exercised central control over branch managers through a cadre of bank inspectors who visited each branch twice a year to minutely check the books and ensure no irregularity. Largely as a result of these procedures, by 1918 Lloyds had become a large and geographically-dispersed bureaucracy employing 10,000 workers in over 1,600 branches scattered throughout the country (Sayers, 1957; Winton, 1980).

\section{Persistence of localism}

Despite Lloyds' formal efforts at centralizing and rationalizing itself as an institution, its modus operandi accommodated localized business and professional relationships in a variety of important respects. We focus on three main ways in which Lloyds responded to traditional status issues from an organizational standpoint. First, authority remained geographically dispersed for many years, in part because Lloyds managed its amalgamation wave by allowing bank directors from absorbed banks limited control over the affairs of their former branches for extended periods after the mergers. Second, the bank continued to rely on its staff's local relationships and knowledge of local conditions in order to make sound judgements about lending decisions. Finally, and perhaps most importantly, Lloyds encouraged bank personnel to maintain the bank's good name through their participation in the local status community. We discuss each of these strategies in turn below. Taken together, these locally-based practices ultimately helped Lloyds remain profitable at the national level, even if each exposed the bank to increased risk at the local level.

Absorption of constituent banks Perhaps the most striking example of Lloyds' apparent willingness to cater to local interests is the prevalence of geographically-dispersed centres of authority. Throughout the period when Lloyds was growing most rapidly (1880-1910), there 
was considerable ambiguity about where the bank was headquartered, with Head Office functions split between the Birmingham Office and Lombard Street in London. During this period, the London Office was responsible for 'town'-based interest rates (traditionally higher than those outside London), whilst Birmingham was responsible for 'country'-based interest rates. It was not until 1910 that Lloyds moved its entire Head Office to London.

Even beyond the issue of the formal centre of authority, the bank's particular pattern of growth through amalgamation meant Lloyds repeatedly faced bank directors of absorbed banks who feared their old customers would suffer under the impersonal regulations of Lloyds' bureaucracy. An early example was the merger with Liverpool Union Bank in 1900. News of the merger caused considerable dismay amongst the Lancashire business community, who claimed that 'Lancashire businessmen should be able to undertake the most delicate negotiations with Lancashire bankers' (Sayers, 1957: 262). Responding to these local concerns, Lloyds agreed to the formation of a 'local committee' made up of the former directors of the Liverpool Union. As late as 1929, Lloyds had local committees in Birmingham, Manchester and Newcastle (LBA, Organization Committee minutes). Similar local committees were formed following other large mergers: the local committee formed following the merger with Wiltshire; and Dorset Bank in 1914 retained the right to sanction overdrafts of up to $£ 15,000$ without reference to Head Office. The Capital and Counties Board continued to meet as an effecting governing body until 1934.

In addition to allowing old directors to retain influence in their local economies, in many regions growth through merger created a dual branch structure within Lloyds. It often took years for duplicate branches to be closed down, and in some cases separate institutional structures were retained following major mergers (for instance, recruitment was kept separate for five years after the merger with Capital and Counties).

Knowledge of local economy and local clients Notwithstanding formal theories of bureaucratic operating procedures, bank managers at Lloyds were not expected to blindly apply abstract criteria for advancing loans or opening accounts; rather, they were encouraged to rely on their own judgement about the standing and status of local customers and businesses. Exercise of this local discretion took many forms, from valuing local property to assessing the credit-worthiness of potential clients.

For the bank to remain profitable, it was essential that branch managers were able to accurately assess local economic conditions in order to determine acceptable overdraft limits. One example of this can be found in the Private Memoranda (PM) book of the manager of Bellingham Branch, ${ }^{6}$ which shows that the local manager regularly spent time visiting farms and valuing stock (LBA, book 129). The need to understand the intricacies of the local economy was not confined to agricultural areas, however. In the 1930s, Lloyds classified each branch according to the nature of its local labour market and expected managers to report back on the general state of the local economy in their annual reports. In this respect, the creation of a national branch structure did not eclipse the need for local knowledge and expertise.

Another example of the pervasiveness of concern with understanding the local community is found in the standard form that bank managers completed when authorizing overdrafts: in addition to details about the value of the security offered, this form also required 'full information as to the standing and character of the intending borrower' (LBA, file 7596). Further evidence of the importance of local status communities for the bank can be found in the 1902 PM book from a manager in Manchester, which includes 220 mentions of the credit-worthiness of customers. However, this manager did not deploy status judgements in ways which countered financial calculations: in 21 instances

6 Private Memoranda books were maintained by branch managers and often contain considerable detail about the daily activities of the manager. 
reference is directly made to the status or standing of the customer, in 13 instances to the age of the account and in 23 instances to the general wealth of the client. What is evident in the PM books is the extent to which managers judged an individual's credit-worthiness in terms that went beyond purely financial calculation. In the rural area of Bellingham, the local manager's decisions about overdrafts depended frequently on valuations of financial propriety. The manager's records indicate how local branch managers tapped into local informational networks and the crucial role this played in allowing the bank to operate effectively.

Staff involvement in local affairs The final way in which Lloyds exploited the residue of its locally-based branch structure was through the involvement of managers and other bank staff in the social relations of particular localities. Throughout Lloyds' history, bank employees were expected to be well regarded locally: bank clerks were to be visible and respectable, and managers were to be upstanding men engaged in civic activities (for instance, as treasurers of local societies). The concern with respectability and position was linked closely to the perception that only staff who knew customers personally would be able to bring profitable business to the bank. Above and beyond simply being visible in local civic affairs, however, bank staff were expected to enhance the position of the bank by maintaining high standing in the local moral community. Lloyds' efforts to monitor and punish bank employees who evidenced 'moral lapses' indicates the seriousness with which Lloyds viewed local reputations. In fact, one of the main functions of the Head Office's Inspectorate Division was to ensure that no local scandal escalate to the point that it affect the bank's standing.

Examples of Lloyds' concern with the local position of its employees are common in the archives of the bank. The annual reports of branch managers on their staff frequently refer to this issue: for instance, one manager noted that Mr Jones 'is an Oxford boy and has a wonderful knowledge of local people and their affairs - he is most useful'. 7 Another manager notes that Mr Hare 'was well known, having been the local manager of Lloyds ever since that well known bank was established in the city. He had taken much interest in the Winsley Sanatorium for consumptives, and was Honorary Treasurer of the Institution. Mr Hare was also an enthusiastic fisherman, was elected President of the Bath Anglers Association and took the chair at its annual dinners'.

Another example reveals Lloyds' particular attentiveness to the moral affairs of its employees. When the Staff Department at Lloyds' Head Office heard a rumour that a bank clerk's wife had deserted him for another man, they launched an inquiry. The clerk's branch manager was asked to provide further details; he wrote back, rather sadly, that:

I think we can rely on Mr Green to do his best to prevent any undue publicity about his domestic troubles in the press or otherwise which might be to the detriment of the Bank. The wife, I understand, still lives in Shinley, but I do not believe that this unhappy affair interests anyone beyond those immediately concerned. Her connection with the bank is quite forgotten now. The morals of some Shinley people are not what they should be, and I regret to say that nobody appears to worry very much (LBA, file 3515 ).

In another instance, Lloyds only allowed one particular clerk to marry when his father in law agreed to subsidize his salary to the tune of $£ 30$ per annum. ${ }^{9}$ This clerk had

7 LBA, file 3515. Here, as in later quotations, personal names and locations have been changed to preserve confidentiality.

8 LBA, file 9685, Manager quoted in the Bath Daily Chronicle. Unfortunately, Mr Hare was arrested for embezzlement in 1911 .

9 It was, in fact, routine practice that clerks had to seek managers' approval in order to marry. The reason was that the bank was concerned that since it was expected that bank clerks' wives would not work, marriage would impose extra spending on the clerk's household which it was not always clear could be borne on a clerk's salary. 
the right social background and seemed to be an excellent employee: his branch manager reported in 1915 that 'he is an excellent officer and a good all round man: well bred, with good manners' (LBA, file 9687). Later it was reported that 'he was an excellent cashier, gentlemanly and of good address'. Nonetheless, he was also a problem, since he was frequently reported to be in regular drinking sessions which gained him a reputation for intemperance. Lloyds chose to move him to different branches rather than sack him because of the fact that he had a powerful patron in his father in law. In 1917, when he fell into debt, his landlord evoked the power of his local network as part of his attempt to get Lloyds to cover the missing rent. The landlord's letter is worth reproducing:

I am the senior clerk to your local solicitor ... and having on account of such position and of the kindness and consideration received from Mr Fredericks [the former manager] and $\mathrm{Mr}$ Smith [the current manager] ... and the other members of the staff when the Ashford Branch was opened, tried to further the interests of the bank among [the solicitor's] clients and a wide circle of my personal friends, it will be readily understood that there has always been a certain amount of mutual good will between the local officials of the bank and myself... [If I go to court] the case being one which is contested would be certain to get into the local papers (LBA, file 9687).

Here, again, local notables remind Lloyds of the importance of recognizing the power of local reputational networks. While, in many instances, the bank staff's good position worked to Lloyds' advantage, local opinion could just as easily work to discredit particular bank staff. In Burslem in 1900, a local solicitor complained that the branch manger was incompetent, largely because he had refused to extend his overdraft. The Head Office Inspector found that these lawyers 'were emphatic on the point as to $\mathrm{Mr}$ Smith's general unfitness for the position at Burslem, and stated that not only had he through his ignorance, want of tact and discretion and other disqualifications missed good business which ought to have found its way to Lloyds, but also spoilt the prospects for a long time of any successor'. One of the partners claimed that he had 'tried by way of introductions at his house and elsewhere', but his conclusion was 'that socially or otherwise Mr Smith will do no good at Burslem'. Subsequent inquiries found that these lawyers had 'lent' Smith $£ 50$ on his arrival to help him settle in. The Inspector notes that 'he is not on friendly terms with his neighbouring Pottery managers'. What is interesting is the outcome: Lloyds' Inspectors bent to local feeling and sacked Smith.

In a few instances, the bank's fundamental interest in running a rationalized and efficient business collided with the desires of the local business community, as in the fascinating case of a banker in Llanelli. In order to preserve the positions of local businessmen ('so as to enable them to make a good position in life'), the Llanelli branch manager 'borrowed' money from the branch to invest into a local colliery. When the fraud was discovered in 1911, unnamed local notables arranged a deputation to the bank offering to repay the money to avoid the manager's prosecution. The local Urban District Council, of which the manager was treasurer, stood by him, refusing to sack him until he had been proven guilty. In this instance, Lloyds refused to be browbeaten and took the case to trial, where the defence council reported that 'the prisoner had done what he did with a view to helping others, and none of the money had gone into his own pocket'. Nevertheless, the former branch manager was found guilty and given three years' imprisonment. Strikingly, on his release, he opened a banking agency locally, even advertising the fact that he was the former manager of Lloyds Bank. It appeared that there might still be room, in Wales at least, for a well-known local banker who put local interests before the profits of the bank. ${ }^{10}$

This case is one of several fraud cases that the Head Office Inspectorate monitored closely in the early decades of the twentieth century. In many of these cases it is clear that

10 LBA, file 3515. It is not recorded whether the manager made a success of his new career. 
what the bank perceived as fraud was not, in fact, an individual branch manager acting in his own self-interest, but rather a bank worker who saw himself acting on behalf of the interests of his broader community. As Green has shown in his study of the behaviour of early English juries, locals struggling to maintain autonomy in the face of newly centralized authority often collude to define events in a fashion more consistent with local tradition than with rational principles (Green, 1985).

The archival evidence suggests that Lloyds Bank sought to incorporate locallyorganized status concerns into bureaucratic structures, even as these structures became more formalized. Many Head Office functions, particularly the Inspectorate, became drawn into a myriad of local concerns, and yet clearly the bank directors did not intend to ruthlessly root out local traditions and relationships that might benefit the bank's business. Rather, central surveillance was designed to ensure, if possible, that employees in particular local contexts were working properly with local communities.

Hence, even while Lloyds sought to rise above the cultural world of the locality, it continued to rely on it, since its own respectability could easily be contaminated at the local level. The Country Manager of Lloyds showed he knew this well enough when, in 1902, he reported that 'we have to consider [that] the effect of an exposure in the heart of our country business might do us serious harm, especially as it would give the opportunity to our rivals to point the finger of scorn at our internal administration in the past' (LBA, file 9679).

\section{Regional migration and bureaucratization in Lloyds Bank}

We now turn to examine the extent to which traces of localism are also revealed in the particular geographic mobility patterns of individual bank employees. The question is, did the continued pressure for localized judgments documented above penetrate Lloyds' emerging bureaucratic employment structures, thereby retaining traditional regional elements within a modern shell?

As noted above, one characteristic aspect of Lloyds' drive toward centralization was its attempt to rationalize its employment system. Several aspects of this attempt are worth noting in light of our interest in patterns of geographic mobility. First, quite early on Lloyds began to develop formal internal career hierarchies for its employees. In 1885 several types of managerial positions were elaborated, and clerical grades formalized; subsequent revisions to these grades in the 1920s made it more difficult for clerks to get a regular financial advance through increments. Hence, over time, higher incomes became increasingly dependent on promotion to higher graded jobs (rather than on tenure with the bank). Second, Lloyds gave each of its branches a salary limit, which meant that workers deemed fit for promotion were often moved to a different branch that had not already met its salary limit. Third, the development of a functionally-oriented management structure, including a large Head Office, specialist Inspectorate, Executor and Trustee Departments based in regional centres and a Colonial and Foreign Office in London, meant that increasing numbers of trusted and experienced senior staff were needed to fill these posts. ${ }^{11}$ Finally, beginning in the 1920 s, the bank recognized the advantages of moving staff from branch to branch in order to enhance their training.

We consider the consequences these organizational innovations had on individual careers by examining yearly work histories for a large sample of Lloyds Bank employees. To do this, we rely on an extraordinary collection of career histories extracted from a source known by Lloyds' archive staff as 'The Bible', which contains the name of every single employee of the bank, regardless of grade, sex or location, who began working for

11 In 1914 only 4\% of Lloyds' workers were employed at Head Office, but this increased to $9 \%$ by 1938 (figures calculated from Lloyds Bank Annual Yearbooks). 
Lloyds between about 1890 and $1940 .{ }^{12}$ Although the volume itself only contains bare information about each employee, it is possible to trace the full career histories of these employees by consulting the branch directories and yearbooks issued by the bank. Lloyds Bank archivists have been carrying out this record linkage as part of their drive to computerize their records, and we have extracted a representative sample of 2,612 male workers for analysis here. ${ }^{13}$

\section{Changes in geographic mobility of Lloyds Bank employees}

We begin by documenting the extent to which different cohorts of Lloyds Bank employees were mobile during the course of their career. Many others have noted the marked rise in geographic mobility among white-collar labourers in the post-Victorian era, and men who worked at Lloyds Bank were no exception. Table 1 describes cohortby-cohort mobility experiences for our sample of bank employees. As with the rest of the bank, our entry cohorts get larger over time; consistent with the typical story of bureaucratization, as the organization gets larger, workers are moved around more frequently. Thus, within Lloyds we see a marked increase in the number of job-related geographic moves among members of later cohorts, relative to men who were hired earlier. For instance, men hired by the bank at the close of the nineteenth century moved only once, on average, during the course of their careers, while men hired in the 1920s were likely to move three or four times.

Table 1 also shows that the increase in the number of geographic transfers translates rather directly into larger total distances travelled during the course of one's career, a pattern that is revealed more clearly in Figure 1. Figure 1 plots the mean distance travelled during men's tenure at Lloyds, by their cohort of entry: here we can see a fairly clear linear increase in miles moved per career and, more strikingly, per year of tenure, with the only noticeable deviation in the trend occurring for men who were hired during the Great War. Hence, as Lloyds grew, so did the actual mobility of the bank worker.

\section{National or local mobility?}

Did the new mobility of Lloyds Bank staff indicate the emergence of a unified, national labour market for white-collar labour, or was this mobility structured in ways that preserved local interests or community relations? We know that successive cohorts of workers were transferred more frequently than their predecessors, and that during the course of their careers men hired later were transferred over longer cumulative distances during their tenure at Lloyds. The final column of Table 2 examines the mean distance (in miles) of moves arranged by the bank for workers hired during successive cohorts. What we notice is that the average distance per transfer fell somewhat over time, a trend that is illustrated graphically in Figure 2. Around the turn of the century, when the bank was expanding rapidly and few employees were moving, the average transfer moved a bank worker to a branch over 50 miles away; after this period, and once Lloyds' national branch structure was fully established, the typical transfer move fell to around 30 miles. And, in fact, for much of the twentieth century there is remarkable stability in the mean distance of transfer.

Hence, while the development of the bank's branch network in the early twentieth century facilitated an increase in geographic mobility among bank staff, it appears that at any given moment workers tended to move over relatively short distances. Such a pattern could be produced by either workers stringing together successive moves that ultimately took them across the entire country, or by mobile bank workers circulating through a

12 In excess of 20,000 workers are contained in the bank as a whole. Because the 'bible' is organized alphabetically, our sample has also been derived alphabetically, and contains the first 4,000 names in the bible. For an earlier study of this data, see Stovel et al. (1996).

13 The 2,612 employees are all men, taken from a total sample of 4,000 employees. We have only examined professional men's careers here since women were employed on female-only grades, with no prospects of promotion, and messengers were not eligible for promotion to clerk. 
Table 1 Geographic mobility patterns among cohorts of Lloyds Bank employees

\begin{tabular}{lcccc}
\hline Entry cohort & $\begin{array}{c}\text { No. of employees } \\
\text { in sample }\end{array}$ & $\begin{array}{c}\text { Mean no. of } \\
\text { geographic } \\
\text { transfers per } \\
\text { employee* }\end{array}$ & $\begin{array}{c}\text { Mean distance } \\
\text { travelled per } \\
\text { career }\end{array}$ & $\begin{array}{c}\text { Mean distance } \\
\text { per geographic } \\
\text { transfer }\end{array}$ \\
\hline $1880-84$ & 71 & 0.62 & 83.59 & 51.94 \\
$1885-89$ & 85 & 0.66 & 84.24 & 48.85 \\
$1890-94$ & 108 & 1.04 & 109.69 & 56.11 \\
$1895-99$ & 157 & 1.22 & 109.73 & 53.62 \\
$1900-04$ & 205 & 2.23 & 132.62 & 39.97 \\
$1905-09$ & 189 & 2.49 & 151.84 & 43.84 \\
$1910-14$ & 361 & 2.06 & 120.85 & 30.25 \\
$1915-19$ & 353 & 2.41 & 127.30 & 31.70 \\
$1920-24$ & 533 & 3.48 & 159.75 & 31.64 \\
$1925-29$ & 410 & 4.47 & 166.63 & \\
\hline
\end{tabular}

* This column refers to the number of transfers for which distance calculations are possible. Some missing data exist; if the branch location of either the origin or destination branch was unknown, the job shift is not included in this column, and is excluded from all distance calculations.

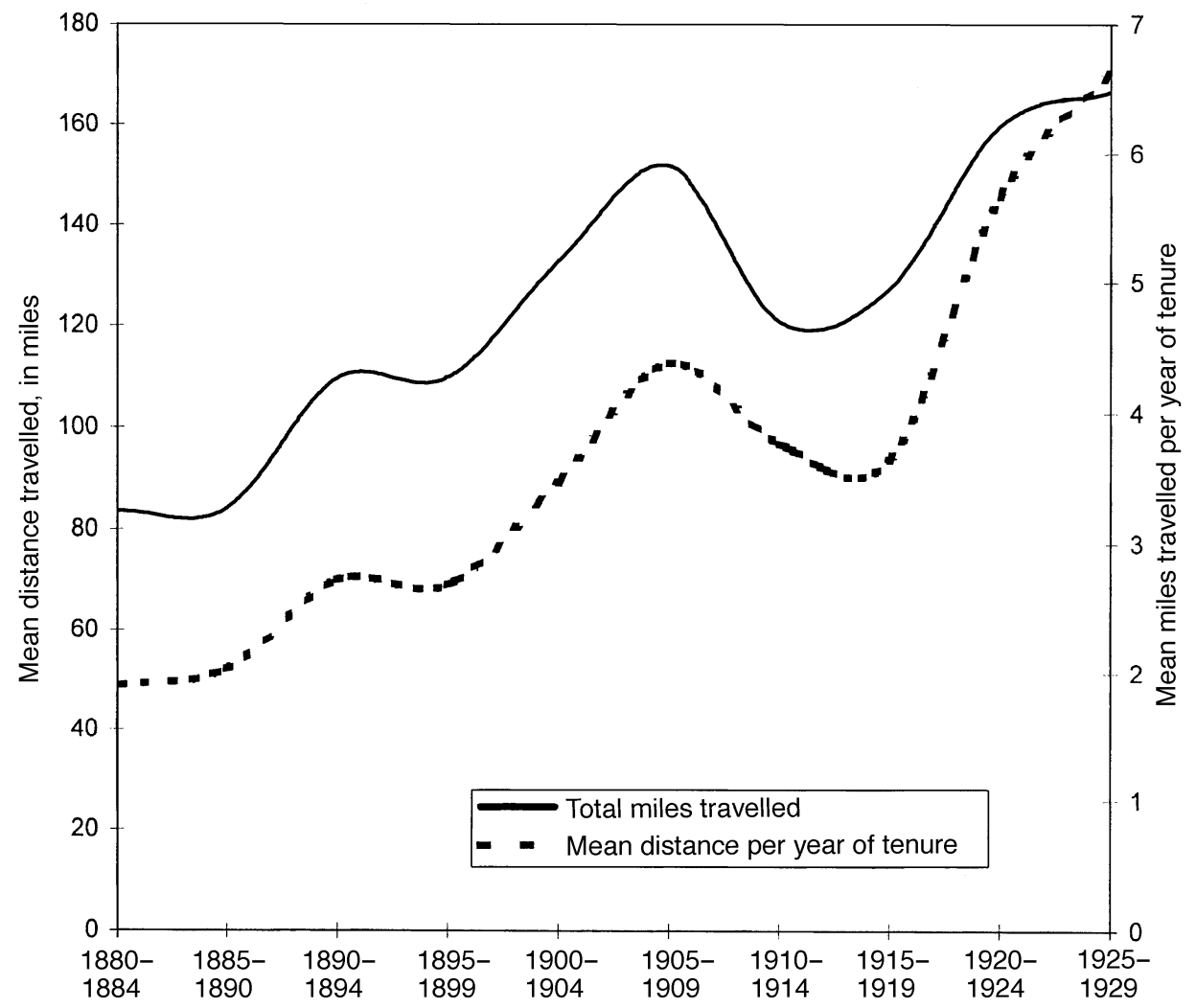

Figure 1 Mean distance travelled during tenure 


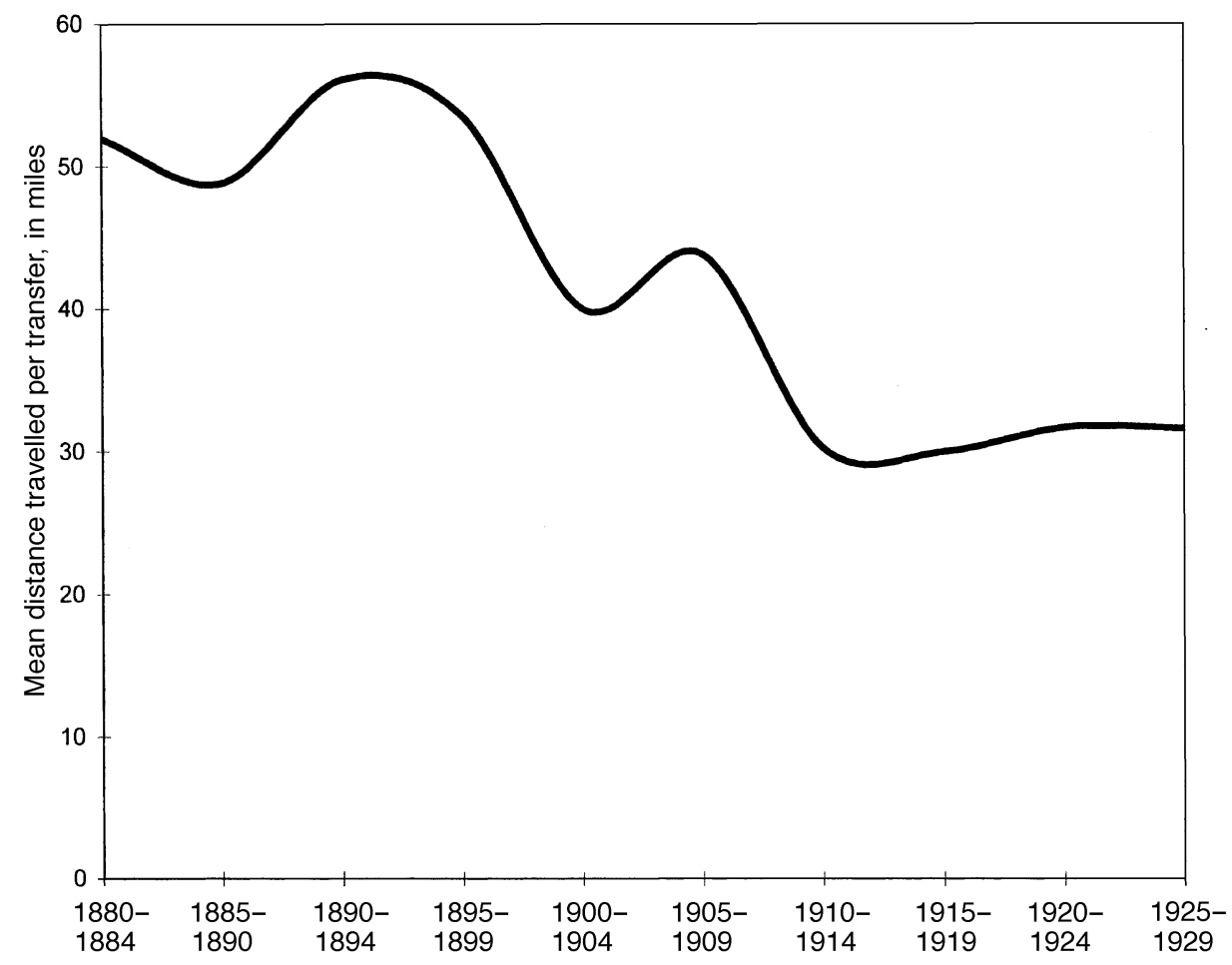

Figure 2 Mean distance of geographic transfer

particular region, perhaps acquiring increasing responsibility along the way, but never sacrificing the potential benefits of local knowledge and relationships. We now examine the extent to which mobility among bank staff fits these patterns.

Table 2 shows the proportion of workers whose geographic transfers took them away from their home counties or region, divided by their cohort of entry. We see that among men who joined prior to 1900 , interregional mobility was fairly uncommon, but by no means rare. For those men entering in the early years of the twentieth century, supra-local mobility became more common, which makes sense when we recall that workers starting in these years had the highest rates of mobility of any cohort in the sample. The war years saw a dramatic fall in rates of mobility, however, especially amongst those who entered between 1915 and 1919. After this period, the structure of mobility stabilized around a largely regional structure: while about half of the bank workers entering Lloyds between 1920 and 1930 ended their working life in a different county, only between a quarter and a third moved between regions.

\section{Particular regions}

Thus far, we have examined the mobility experiences of individual workers in order to shed light on the extent to which staffing patterns facilitated both the preservation of relational banking and the emergence of a more mobile and cosmopolitan class of whitecollar labourers. However, we have ignored the role that specific regions and urban centres played in this process. Table 3 reveals the extent to which various regions 'retained' their employees: each row reports the proportion of employees beginning in a specific region who ended their careers in one of the other regions. The main diagonal cells of the table show the proportion of workers who ended their careers in the same region in which they were hired; since in all regions well over $50 \%$ of all employees 
Table 2 Intercounty and interregional migration*

\begin{tabular}{lccc}
\hline Entry cohort & $\begin{array}{c}\text { No. of employees } \\
\text { in sample }\end{array}$ & $\begin{array}{c}\text { Percent changing } \\
\text { counties }\end{array}$ & $\begin{array}{c}\text { Percent changing } \\
\text { regions }\end{array}$ \\
\hline $1880-84$ & 71 & $1 \%$ & $1 \%$ \\
$1885-89$ & 85 & $4 \%$ & $4 \%$ \\
$1890-94$ & 108 & $1 \%$ & $1 \%$ \\
$1895-99$ & 157 & $1 \%$ & $1 \%$ \\
$1900-04$ & 205 & $15 \%$ & $11 \%$ \\
$1905-09$ & 189 & $25 \%$ & $18 \%$ \\
$1910-14$ & 361 & $12 \%$ & $7 \%$ \\
$1915-19$ & 353 & $2 \%$ & $1 \%$ \\
$1920-24$ & 533 & $51 \%$ & $27 \%$ \\
$1925-29$ & 410 & $54 \%$ & $33 \%$
\end{tabular}

* This table contrasts county and region of first job with county and region of last posting while employed at Lloyds.

remained in their region of origin, the dominant pattern was clearly regional stasis. This pattern is particularly strong in the larger regions where the bank had a strong presence and could move staff from branch to branch without losing the advantages of regional experience; by contrast, the small regions of East Anglia and Wales see a considerably higher proportion move away.

This pattern of geographic mobility is consistent, not with the existence of a uniform national labour market, but, rather, with the persistence of a regionally-structured class of bank staff. Archival material suggests a rationale for this pattern. In the late 1930s, Head Office proposed allowing greater mobility of employees within Wales; their initiative met with the objection that: 'It has always been recognised that the people of North Wales do not mix easily with the South Wales folk, and vice versa. As a consequence, extremely few staff transfers in either direction have ever been suggested or brought about' (LBA, file 5577). Even as late as 1944, the need to appease local culture was still recognized. When the manager of Porthcawl asked to be moved to fill the vacancy at Neath, he wrote to the Head Office that 'possibly Head Office will think that someone either Welsh speaking or of Welsh nationality should go there, but from my knowledge of that town, this is not essential and in my own case a few words of Welsh together with a Welsh speaking wife from a very well known local family would be more than sufficient' (LBA, file 10159). Especially in Wales, some type of identification with a local region was a valuable business asset well into the twentieth century.

Table 3 Outflow from regions of origin

\begin{tabular}{lccccccccrr}
\hline & $\begin{array}{c}\text { East } \\
\text { Anglia }\end{array}$ & London & Midlands & North & $\begin{array}{c}\text { North } \\
\text { West }\end{array}$ & $\begin{array}{c}\text { South } \\
\text { East }\end{array}$ & $\begin{array}{c}\text { South } \\
\text { West }\end{array}$ & Wales & Number \\
\hline East Anglia & 0.59 & 0.07 & 0.07 & 0.00 & 0.01 & 0.23 & 0.03 & 0.00 & 87 \\
London & 0.00 & 0.83 & 0.03 & 0.00 & 0.00 & 0.10 & 0.03 & 0.01 & 795 \\
Midlands & 0.02 & 0.13 & 0.62 & 0.01 & 0.02 & 0.11 & 0.07 & 0.02 & 522 \\
North & 0.01 & 0.09 & 0.02 & 0.77 & 0.08 & 0.03 & 0.01 & 0.00 & 200 \\
North West & 0.01 & 0.12 & 0.07 & 0.07 & 0.64 & 0.08 & 0.01 & 0.00 & 90 \\
South East & 0.02 & 0.12 & 0.05 & 0.00 & 0.01 & 0.70 & 0.08 & 0.01 & 522 \\
South West & 0.01 & 0.07 & 0.05 & 0.00 & 0.00 & 0.17 & 0.69 & 0.01 & 357 \\
Wales & 0.00 & 0.09 & 0.18 & 0.02 & 0.02 & 0.03 & 0.07 & 0.59 & 92 \\
\hline
\end{tabular}


Beyond the overall regionalism, many of those workers whose careers did take them to a new region ended up working in neighbouring regions. For example, of those workers hired in Welsh branches, extremely few were ultimately posted to distant regions. Those staff initially hired into branches in the South West who left were sent mainly to the South East or London, those from the North West go mainly to the North East and London, and those from the North East go to the North West. This pattern suggests further that far from creating a staffing system that rested on the complete transferability (and equivalence) of workers, Lloyds tended to keep workers in or near their local communities, even as those same workers became increasingly mobile.

The final issue we address with the employment data is the extent to which London played a particular role in Lloyds' mobility. Others have suggested that one of the major changes in the social landscape of Great Britain in the nineteenth and early twentieth centuries was the rise of London as a centre of economic and industrial life. With respect to the specific case of Lloyds Bank, there are two reasons to expect that London might have a distinctive place in the network of staff mobility. First, by 1910, Lloyds' Head Office functions were firmly established in London. To the extent that the bank began to require a more professional managerial staff, we would expect that ensuring that future managers spent some time in London would become a more critical feature of Lloyds' staffing arrangement. Second, during the early years of the twentieth century Lloyds opened or acquired a large number of branches in the greater London area, employing larger and larger numbers of clerks. For instance, in 1900 only $5 \%$ of clerks began in London, but as more branches opened in London in the interwar years this proportion rose, such that over $20 \%$ of those entering after the 1920 s initially worked in London. It is possible that these two factors combined to create a staffing system organized around a London hub, with spokes leading to the various regions of England and Wales.

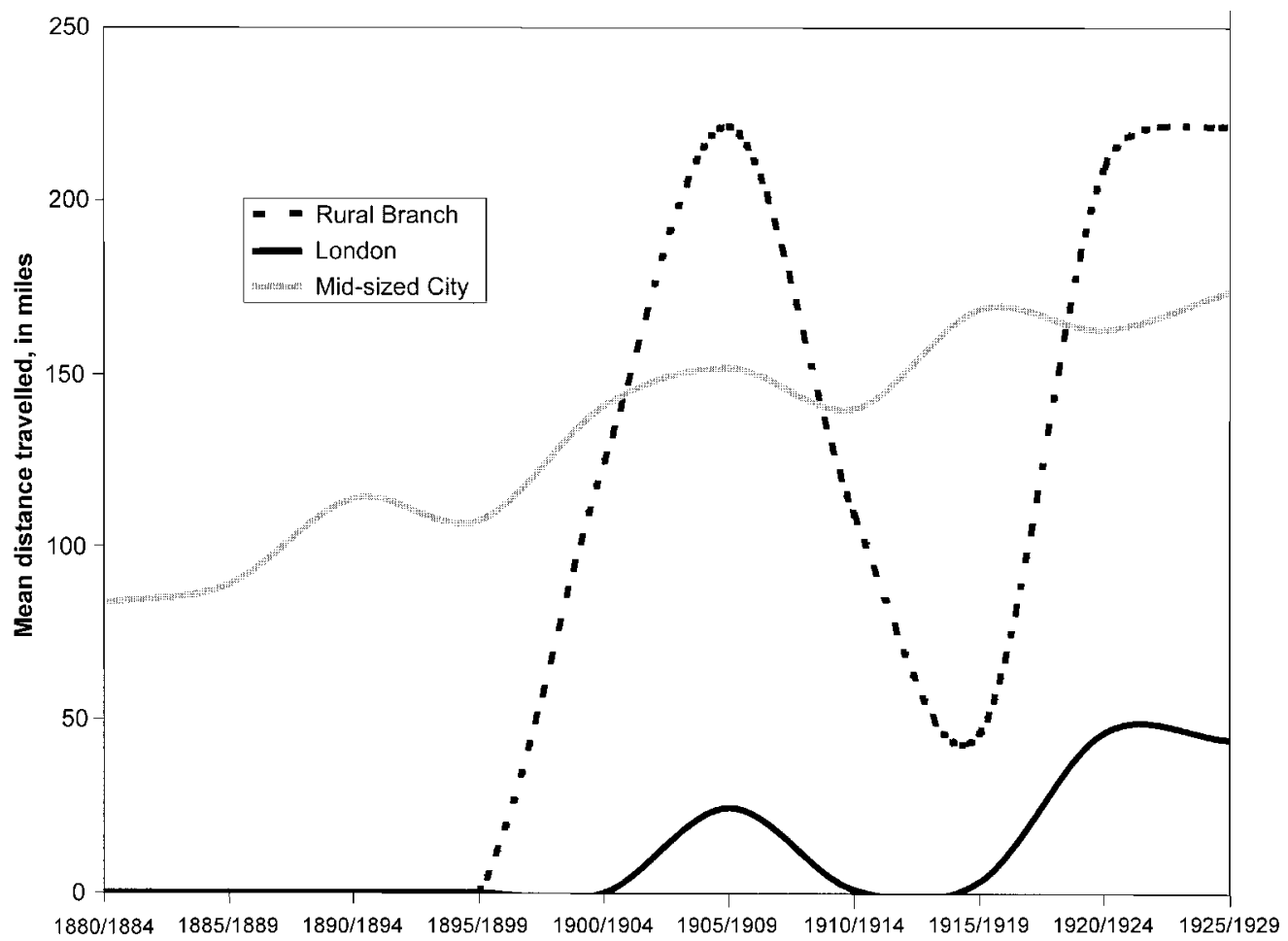

Figure 3 Mean distance travelled by originating branch type 
Figure 3 breaks down the career-long mobility experiences of bank staff originating in small rural branches, in London branches and in other types of branches (mostly in medium-sized urban areas), and shows how the spatial mobility of these different types of entrants changed over time. ${ }^{14}$ These data reveal quite clearly that before 1915 , London men rarely moved at all. This was in part structural: London-based employees were paid on different grading systems, reported to different managers and were not expected to mix with their country colleagues. This situation changed, however, after 1920, at which point the spatial mobility of London workers rose dramatically, especially for those entering in the 1930s, when Lloyds explicitly encouraged the outward flow of London workers to the regions. It was only beginning in these decades that the London labour market began to be more fully integrated with that of the provinces and that the bank directors encouraged the outward flow of London workers to the more distant regions. In contrast, employees from smaller urban areas and particularly from rural branches had begun to be quite mobile much earlier on, though, again, the trend was interrupted for the small cohort hired during the war. Thus, overall, interregional migration was generally rather unusual, with the vast majority of geographic mobility covering quite small distances. Movement to and from London was the main exception, though even this was relatively rare: before the mid1920s, provincial workers might be temporarily posted to London but, by contrast, very few London workers moved elsewhere.

\section{Conclusion}

Archival records maintained by Lloyds indicate that in the midst of the drive to rationalize the operations of the bank, local interests and concerns continued to influence the business of banking at the branch level. We find that even as Lloyds developed into a modern, efficient, national bureaucracy, it consolidated localized cultures in three distinctive ways: by developing career structures that strengthened regional cultures; by putting in place a new kind of spatial division between London and the provinces; and by continuing to attend to the position of its employees in their own local communities. While major changes occurred in the structure of the career paths of Lloyds Bank employees, even the newer employment relations allowed for the expression of local interests within the national structure.

It is obvious that as long as local communities could organize status arrays or articulate local business interests, banks - whatever their national aspirations - could not easily impose centralized control over branch managers without risk of business failure. Equally clear, once local business interests transcended locality, formalized banking practices could be applied with success. As the frame of reference for the local middle classes, initially rooted within specific communities, expanded, Lloyds was both handmaiden to localist interests and midwife to a national middle class. Consolidation of formerly discrete bank groups into large clearing houses paved the way for middle-class 'sensibility', though this path was built, not from above, but, rather, by a careful nurturing of largely provincial economic activities.

Our analysis suggests that the newly mobile middle class did not necessarily float free of local attachments, but rather - through their patterns of mobility - represented a way of connecting locales, a way of re-inscribing places in biographies of the middle class. In this respect, we see mobility as a means of re-embedding the local within bureaucratically-organized and administered career structures. Hence, despite the fact that

14 While there was an increase in the proportion of bank staff hired into urban branches over time, sizeable proportions continued to come from small rural areas. Very few rural clerks were recruited in the first world war, but in the 1920 s and 1930 s a third or so of new entrants continued to be found in small rural branches. 
many white-collar labourers worked in increasingly rationalized organizations, the newly emergent British middle class continued to be fundamentally rooted in spatiallyorganized networks.

In terms of bank workers' careers, there is little evidence of growing spatial mobility at Lloyds over the early twentieth century if this is measured in terms of distance travelled when workers transfer between branches. Increases in aggregate spatial mobility are due almost entirely to increases in the number of transfers that took place; in fact, the distance travelled per move actually fell as the twentieth century progressed. Thus, the elaboration of an extensive national branch network allowed workers to be moved more intensively within regions. If there was a national middle class, clerks could be moved at random from one community to another and be equally effective. That mobility was strongly circumscribed by region indicates that the process of class formation, for the middle as well as working class, was strongly influenced by spatial context.

Equally surprising is the fact that we find no evidence for mobility across major provincial cities - for example Manchester to Ipswich, or Norwich to York. While these cities were structurally equivalent with respect to their position in local (regional) economies and the national economy centred in London, they were clearly associated with a different cultural and social foundation for the middle class. What worked in York did not work in Birmingham. The expansion of economic activity retained its regional focus for longer than one might expect.

The bank's new structure meant that spatial mobility and promotion could take place within regional settings, and the amount of genuine spiralism should not be exaggerated. In this respect, Lloyds did not constitute an undifferentiated or impersonal nationallybased labour market; rather, the picture that emerges is one of resilient localized communities, even within an increasingly national bureaucratic bank. Insofar as change took place, it was a change from the status community of the small town or village to the region, so that the middle classes might be recognizable at a somewhat higher spatial scale, but still one well below that of the nation as a whole.

Further, our data show that London played a key role within this structure. While London had long reigned supreme among British cities, Rubinstein (1987) has shown the considerable concentration of wealth in the area in the Victorian period. In the course of the twentieth century, however, this dominance took on new forms as many expanding organizational hierarchies chose to locate their headquarters there. Whereas, in the Victorian period, regional economies had a high degree of autonomy and could find most of the services they needed within their region, the development of large national and multinational firms steadily reduced the integrity of regional economies and led to them becoming increasingly dependent on services located in the South East (Lash and Urry, 1987). Doreen Massey (1984) has shown how this has helped to produce a 'spatial division of labour' in which the 'control functions' of management, research and planning are concentrated in London, whilst more routine activities are carried out elsewhere.

There are clear echoes of these developments in the history of Lloyds Bank. Once London became the undisputed centre of the bank's activities in 1910, other regions became more dependent on London. London was the one place to which bank workers might be posted from anywhere in the system, and after 1920 it also sent out its clerks to other areas. Ultimately, London became the hub of the system, both absorbing and emitting bank staff, and, as a result, non-Londoners were more likely to move in the course of their careers than Londoners were, while Londoners were able to gain promotion without moving elsewhere. Nevertheless, it is likely that the demand for more highly-trained regional managers played a crucial role in enhancing the hegemony of London over the regions. Geographers have argued that in the 1970s, London and the South East acted as an 'escalator' region, in which young people were drawn to the area from outside, earned promotion quickly and went back to the regions having earned 
promotion (Fielding, 1989; Savage et al., 1992). The Lloyds' data suggest that such a pattern may go back to the first world war.

Hence, although Lloyds was increasingly a national institution, it sought to simultaneously benefit from and regulate local affairs. Banks gained their standing and prestige, and ultimately, therefore, their business, by being trusted, respectable constituents of what they perceived to be a distinct local community. To be successful, Lloyds had to deal with powerful local business and status communities who expected to be influential in banking matters and who expected the local Lloyds' branches to be responsive to the local community as much as to Head Office. As the fraud cases illustrate, the persistent danger was that local bank workers would be so aligned with the interests of the local community that they would put these concerns above the overall effectiveness of the bank.

The idea that a fully developed cosmopolitan middle class simply replaced traditionally-organized local status hierarchies cannot be supported by the Lloyds' story. Truly national middle classes could not form easily within large organizations that were so dependent on the existing status communities of the rural areas. If Lloyds had subordinated local concerns, and had randomly moved employees across the country before its customers were ready to entrust their funds to non-local bankers, the firm would have shortly been a candidate for absorption itself. Instead, Lloyds continued to allow local branch managers a certain amount of autonomy, and moved employees to nearby branches when staffing needs required it. In this way, Lloyds (and other emerging bureaucracies) both contributed to, and responded to, the formation of a class of mobile white-collar labour.

Mike Savage (M.Savage@man.ac.uk), Department of Sociology, University of Manchester, Manchester M13 9PL, UK, Katherine Stovel (stovel@u.washington.edu), Department of Sociology, University of Washington, Box 353340, Seattle, WA 989153340, USA and Peter Bearman (psb17@columbia.edu), Department of Sociology, Columbia University, 413 Fayerweather Hall, 1180 Amsterdam Avenue, New York, NY 10027, USA.

\section{References}

Bell, C. (1968) Middle class families: social and geographical mobility. Routledge, London.

Birch, A.H. (1959) Small town politics. Manchester University Press, Manchester.

Blau, P. and O.D. Duncan (1967) The American occupational structure. John Wiley, New York.

Cain, P and A. Hopkins (1992) British imperialism. Longmans, London.

Crompton, R. (1998) Class and stratification. Polity Press, Cambridge.

Daunton, M.J. (1989) "Gentlemanly capitalism"' and British imperialism. Past and Present 122, 119-58.

Davidoff, E. (1973) The best circles: society, etiquette and the season. Croom Helm, London.

Dennis, N., F. Henriques and C. Slaughter (1956) Coal is our life. Eyre and Spottiswold, London.

Erikson, R. and J.H. Goldthorpe (1992) The constant flux. Clarendon, Oxford.

Evans, G. (ed.) (1999) The end of class politics? Clarendon, Oxford.

Fielding, A.J. (1989) Interregional migration and social change: a study of South East England based on the Longitudinal Study. Transactions of the Institute of British Geographers 14.1, 24 37.

Frankenberg, R. (1966) Communities in Britain. Penguin, Harmondsworth.

Gilroy, P. (1994) The black Atlantic. Verso, London.

Gould, R. (1995) Insurgent identities. University of Chicago Press, Chicago.

Green, T.A. (1985) Verdict according to conscience. Chicago University Press, Chicago.

Johnson, J.H., J. Salt and P. Wood (1974) Housing and the migration of labour in England and Wales. Saxon House, Farnborough. 
Katznelson, I. (1988) Marxism and the city. Oxford University Press, Oxford. and V. Zollberg (1986) Working class formation. Princeton University Press, Princeton, NJ.

Koditschek, T. (1994) Class formation and urban-industrial society, 1750-1850. Cambridge University Press, Cambridge.

Lash, S. and J. Urry (1987) The end of organised capitalism. Polity Press, Cambridge.

LBA (Lloyds Bank Archives) Files (various). Lloyds Bank, London.

Lefebvre, H. (1991) The production of space. Blackwell Publishers, Oxford.

Lynd, R.S. and H.M. Lynd (1924) Middletown: a study in American culture. Harcourt Brace, New York.

Massey, D. (1984) Spatial divisions of labour. MacMillan, London.

Morris, R.J. (1990) Class, sect and party. Manchester University Press, Manchester.

Musgrove, F. (1963) The migratory elite. Heinneman, London.

Parsons, T. (1959) The social structure of the American family. In R.N. Anshen (ed.), The family: its function and destiny, Harper, New York.

Rae, J. (1902) The country banker. Harrods, London.

Rubinstein, W.D. (1987) The geographical distribution of middle class income in Britain, 1800 1914. In W.D. Rubinstien (ed.), Elites and the wealthy in modern British history, Harvester, Brighton.

Savage, M. (1987) The dynamics of working class politics. Cambridge University Press, Cambridge.

_ (1988) The missing link: the relationship between spatial mobility and social mobility. British Journal of Sociology xxxix.4, 554-77.

- (1993) Career mobility and class formation: British banking workers and the lower middle class. In A. Miles and D. Vincent (eds.), Building European society: occupational and social mobility in Europe, 1840-1940, Manchester University Press, Manchester.

- (2000) Class analysis and social transformation. Open University Press, Milton Keynes.

— - J. Barlow, P. Dickens and A.J. Fielding (1992) Property, bureaucracy and culture: middle class formation in contemporary Britain. Routledge, London.

Sayers, R.S. (1957) Lloyds Bank in the history of English banking. Clarendon, Oxford.

Smith, D. (1982) Class and compromise: class formation in English society. Routledge, London. Southall, H. (1991) The tramping artisan revisits. Economic History Review XLVI.2, 272-96.

Stacey, M. (1960) Tradition and change. Oxford University Press, London.

Stovel, K., M. Savage and P. Bearman (1996) Ascription into achievement: models of career systems in Lloyds Bank, 1890-1970. American Journal of Sociology 102.2, 358-99.

Watson, W.F. (1960) Social mobility and social class in industrial societies. In M. Glucksmann and E. Devons (eds.), Closed systems and open minds, Aldine, Chicago.

Whyte, W.F. (1957) The organization man. Touchstone, New York.

Winton, J. (1980) Lloyds Bank, 1918-1969. Oxford University Press, Oxford.

Wright, E.O. (1985) Classes. Verso, London.

_ (1996) Class counts. Oxford University Press, Oxford. 